\title{
Questions Raised by the Nuclear Power Accident of March 11, 2011
}

\author{
SHIMAZONO Susumu*
}

\section{Research Report from Germany's Ethics Committee}

Germany immediately established an ethics committee and decided to abandon nuclear power after the March 11 Fukushima nuclear power plant accident, which indicates that nuclear power plants are an ethical issue. The reason that the ethics committee was formed is included in the report. Germany's action subsequently had a tremendous impact on Japan. Ethics are an important issue in social policy; in fact, I believe the concept that ethics is the determinant factor has tremendous resonance in Japan.

What is the definition of ethics in the joint venture report for safe energy in Germany? There are about fifteen people on the committee, of whom three are representatives of Christian churches. There are some scientists, but there are more committee members in the humanities. Of course safe energy is a problem of science and technology, but it is also an issue of public policy and the choices we make about how to live. I think that's the realization.

Looking at the content of the report, however, it is written comparatively logically. What appears in the report is the "concept that is key to ethical value judgments is having sustainability and responsibility." As we heard a few minutes ago, the German committee's fundamental concept is sustainability and responsibility for future generations. This is also paraphrased as the interaction between humans and nature or the relationship between society and nature.

When it comes to ethics in Christianity and European culture, we are not simply talking about rules. Naturally, our sense of values is based on culture. While we inherit our sense of right and wrong from our traditions, we also formulate our own sense of values. In Europe, the consensus is that humans have the responsibility to protect and pass down the environment granted to them from God. It is a position based on the inheritance of religious tradi-

* Shimazono Susumu 島薗進 is a professor in the Faculty of Theology and director of the Institute of Grief Care, Sophia University 
tions.

There is a term called "ecological responsibility," which means to preserve and protect the environment, not to destroy one's own environment, but to maintain it for future generations. There were four conditions in $\mathrm{Mr}$. Kusajima's presentation that exactly describe the ethical responsibilities for addressing this issue.

It isn't right for people to do all the things that are technologically possible. It is a concern that people have no compunction about doing things if they are economically profitable.

The German ethics committee is concerned about nuclear problems, but there has been an ethics committee for the life sciences since long before that. That committee deals with issues such as designer babies, regenerative medicine, human enhancement, and pre-selection of the gender of babies.

An important issue is that people may end up becoming inhuman humans. Some people call this post-human. This is the type of development which can happen in the life sciences. Some people now desire to do these things, and because medicine cannot refuse them, such things happen. The question of how to stop these things from happening is quite serious and also extends to these problems.

The German ethics committee has gone in the direction of abandoning nuclear power in this way. We will gain strength from choosing a new direction. I am saying that in order to achieve this, it is necessary to consider the cultural, social, economic, individual, systemic, and overall picture. Although this is a problem of science and technology, it affects life overall. That is how I think of it. Since that is the case, I think that it naturally leads to the dimension of religion and ethics.

I think that we have naturally come to understand this after having experienced the Fukushima disasters. What struck me as particularly apropos a few minutes ago was the conflict between the farmers and fishermen of the Ariake Sea. Professor Tanaka said that this was an occurrence of a ripping apart of the heart, and I think that Fukushima had a tremendous impact in this way.

I think the reason this occurred was, in short, that the entire environment was destroyed, the base of which was damage to health from radiation. In such an unlivable environment, even if people continued to live there, various activities, such as playing outside and living with the environment, were taken away from them. Many conflicts have arisen in this milieu. I strongly feel that this was the case.

I also joined the Citizen's Commission on Nuclear Energy and was in charge of thinking about the overall picture of damage. Actually, the entire life structure was destroyed. This is what caused the division of the commu- 
nity. There are probably many kinds of damage, such as bad rumors, but the worst damage was that of division.

Even inside families, opinion was divided. Generations were at odds; the older people wanted to stay, while the younger generation wanted to leave. People are needed to take care of the elderly who stayed behind, but no young people would come forward. You can't force them because that will cause more conflict. I think this problem is still happening today. I think you can probably understand how problems that were latent in nuclear power plants were revealed to a large extent in the Fukushima disasters.

\section{Declaration by Religious Groups for Abandoning Nuclear Power}

This is also in the declaration by the Japan Buddhist Federation. It came out on December 1, 2011. Since most of the traditional Buddhist sects belong to the Japan Buddhist Federation, we can say that this is a declaration that was made on a Buddhist foundation or on a common Japanese religious base regardless of doctrinal differences or differences in faith.

What was invoked first - and this is probably different from the German declaration-was that we must always remember that the victims are always in a situation of having their entire lives ruined. I think that continues to be the case. There are probably still several tens of thousands of evacuees.

And in the minds of those who remain, there is always the thought of harm from radiation. And they don't know what is going to happen in the future. They are suffering, having no prospect of figuring out how to recover. In particular, there is anxiety for the children. This is, of course, concern for future life. Through the nuclear power plant disaster we have experienced acutely what has been destroyed.

It goes without saying that this is inextricably linked to our experience with the nuclear bomb. That is also mentioned in the Japan Buddhist Federation declaration. That can be said in the words "inochi (Life)" and "peace." We have had the experience of depending far too much on military might during World War II and heading toward militarism as a means to solve all matters militarily. In that process we experienced having nuclear bombs dropped on us. We should have reflected on this outcome, but instead we have suffered again from the same kind of nuclear damage. The backdrop to this situation is that we did not think enough about the people whose lives were threatened by the nuclear power plant. And as we just heard Professor Tanaka and Mr. Kusajima say, in a myriad ways we are being confronted with the gap between the enormous sums of money that are being pursued and what we think of as activities to foster life in the lifestyles of regional areas. I think this also receives attention in the declaration.

In the pursuit of convenience large amounts of money are involved, and 
there is tremendous profit to be made. It seems like it is convenient for many people, but in reality, it is destructive. I think there are elements that threaten life and peace hidden in it. In very characteristic language, the Japan Buddhist Federation declaration states, "we must not desire to create wealth on the back of some victim, but to choose a path where personal happiness and ethical welfare are in harmony."

Nuclear power is built on the backs of victims. The workers, laborers who work at nuclear power plants, are from the outset exposed to unnecessarily high levels of radiation. That is why they suffer from health hazards, but we overlook them. Every time there is an accident the local people incur great damage.

But there are profits within reach, that is, subsidies are scattered around that local area. That is why tremendous advertising fees are expended to spread the myth of safety. This is how predictable harm and all sorts of disadvantages are covered over. Such victims existed in the past, in the current age, and above all, will become victims in future generations.

The German declaration emphasizes the responsibility to future generations. In contrast, when you look at the various declarations of organizations, especially of religious organizations, after Japan's nuclear power plant accident, nuclear power is built on a foundation of sacrifice. Takahashi Tetsuya and others talk about the structure of sacrifice, while comparing it with Okinawa, and I think this is the unique characteristic. I think that in Germany, even if society tries to sacrifice those in weak positions, the structure does not allow this to happen as readily as in Japan.

However, the characteristic of the religious world is that in such times people reexamine themselves. People take stock of how they have lived up until now. People accept each thing as their own problem. They say, "Escape from excessive material desire; know what is enough; live a life that is humble in the face of nature." This is a very religious thing to say. Thus, in one way we might say it is desirable and easily understandable by many people. Depending on how one thinks of it, and this is true from a religious point of view, but it could be considered cruel to ask average society members to follow this. If this results in a smaller-scaled economic structure, there is a fear that there will be people whose economic activity will be hampered. I think that gives room for counterargument to what is said in this declaration.

The declaration from the German ethics committee and the one put out by Japan's religious groups, as well as ethical issues, form the basis for evaluation of the nuclear power station problem. For example, the court ruling on the lawsuit for the shutdown of the Ōi nuclear power plant in Fukui Prefecture was made in May, 2014, and the ruling did indeed contain this 
type of language.

Most rulings on lawsuits in Japan on nuclear power plants up until this time were made on the side of those promoting nuclear power. This [the Ōi nuclear power plant] was a big turning point. One of the biggest issues involved was ethics.

The representative of the plaintiffs in the suit to shut down the Ōi nuclear power plant was the head Buddhist priest, Nakajima Tetsuen. He is a local person from a temple with a long and distinguished history in Obama, Fukui Prefecture. When you meet him, he truly exudes a Buddhist essence. He was involved in this problem for many years and so took on being the representative in the lawsuit. The reason there are Buddhist elements in the ruling is because of the judge's discernment, but I think it also comes from the structure of the lawsuit.

Here what is suggested is that basic to the ruling is respect of personal rights in the Constitution. The experience with Fukushima is also a large factor. Here I will quote Nakajima Tetsuen. He applied the Buddhist spirit by saying about the problem of ethical responsibility, "harmony for oneself and others; have few desires and know what is enough."

He tried to find a way for the Buddhist tradition to deal with current environmental problems. Or put the other way, Japan's religions had not been putting sufficient effort into this issue. In the case of Germany, debates on environmental issues or life science issues have been proceeding within Christian churches and are reflected in politics. In terms of the spiritual and cultural or ethical dimensions, debate is based on a religious culture and is adequately reflected even at academic conferences. Such debate is also reflected in the courts and in government policies.

In the case of Japan, there is effort made by scientists, as is true in the talks we are having today, and there are steady efforts at activities in regional areas by politicians. There is some cooperation from scholars in the humanities but I think they have not been able to go so far as to have the confidence to debate issues on a spiritual or cultural dimension. I think there is a seachange on this point occurring right now. We can point to personal rights and the ruling based on Articles 13 and 25 of the Constitution.

And getting back to Nakajima Tetsuen, he is referring to "Path to a Zero Nuclear Plant Society" published in April, 2014 by the Citizen's Commission on Nuclear Energy. In that document ethical viewpoints were emphasized.

I have been discussing Buddhism so far, but there is also a declaration issued by the Catholic Bishops' Conference of Japan. The declaration was put out in November 2011, and thus predates the one by the Japan Buddhist Federation. Other Christian churches also issued declarations around the same time. 
At the outset, the Catholic Church regretted that it did not issue a declaration calling for the ban of nuclear power plants before the 2011 Fukushima power plant disaster occurred. The same is true of the Protestant churches. Of course, there are still people in the Catholic Church, Protestant churches, and Japan Buddhist Federation who take the position that it is all right to proceed with nuclear power, however.

In this milieu, the fact that some among them dare to manifest their intentions as groups means that they are putting much effort into the project and as they have discussed the issues among them, they have managed to come to the point they have reached today. I think this is what has changed in the last three years for both the Catholic Church and the Protestant churches. In both instances, call it the mainstream perhaps, but the majority have taken the position that nuclear power is not appropriate for the wellbeing of humanity or that they cannot approve of it in principle. I think the Fukushima disaster has been a large factor in this turn-around.

Responsibility for future generations is greatly emphasized in the declaration by the Catholic Church. At the same time, it emphasizes the myth of safety, or in other words, that a great falsehood is part of nuclear power. This also receives attention in the several declarations issued by the religious world.

Also, nuclear power has the characteristic of causing division. As is stated in the German declaration, it will be by sharing the objective of abandoning nuclear power and adopting renewal energy that we can transcend social divisions. This can also be given as an example.

Here, too, this is being said based on Christianity. The Catholic Bishops' Conference of Japan takes into consideration Japanese culture and says that Japanese Catholics can share a commonality with Shinto and the Buddhist religions. While the premise is that there are differences in culture and religion, they demonstrate a consciousness of finding ways to transcend those differences.

This is where the term "honest poverty" comes into play. I mentioned earlier the Buddhist expression, "have few desires and know what is enough," but "honest poverty" is also found on the Christian side, and is often seen in the lives of Catholic clergy. This is what they are saying.

As I mentioned earlier, this doesn't appear much in the German ethics report. If they stress this point, they will invite the counterargument, "but isn't economic development important?" In order to reach wide agreement it is perhaps best to delay using these expressions.

As a long-term goal, the concepts of not squandering resources, not destroying the natural environment, not being wasteful, and not using excessive amounts of energy are central to a sustainable lifestyle. In terms of a 
time axis, I don't think this can be realized right away. In that sense, the declarations made by the religious world do not say much about this.

I have written my own opinions about this. Would many people choose to resign themselves to a life of honest poverty? This might be all right as a religious declaration aimed at those inside religious organizations, but when it comes to public spaces, I think it is somewhat lame.

What I have been discussing so far is the declarations, but I think that what the focus should be here in terms of the relationship between nuclear power and religion is that religion has put down roots in regional communities. They cannot be cut off from regional environments. As I touched on a few minutes ago, the government and prefectures look at the overall picture, and adhere to using very large budgets. Accordingly, they value what can be done in that way.

In contrast, people in local cities, towns, and villages know what is important based on their own personal experiences. I think there is a gap between the two sides. When it comes to which side religion is closest to, it is clear that it is closer to local communities.

For example, if the Buddhist temple priests left the community, the basis for their livelihood would disappear. Even if they oppose nuclear power, they can't leave. They are in an extremely difficult position.

\section{The Nuclear Power Plant Disaster and Activities by Religious}

In this milieu, they work together with the people who have remained behind. Their representative is the chief monk at Jōenji Temple in Fukushima City, Abe Kōyū. He has been working on decontamination. Of course, the government has been doing decontamination on a large scale, but the first six months to one-year period the government did almost nothing at all. Nevertheless, children were living in that environment. No matter how many times they asked the bureaucrats, they did nothing, so the Buddhist priest decided to do the work himself.

In areas where the doses for soil decontamination were high, Monk Abe piled the soil up in his own temple grounds. The temple is in the outskirts of town and so has some land and mountain forests. Thus, he provided his own land and took responsibility for decontamination himself.

I joined him in this effort. There is a school route on the side of the temple. The route still had a level of twenty millisieverts per year here and there for one year, two years, even three years after the disaster. Such places have to be decontaminated frequently. Monk Abe has been doing that the entire time. Jōenji Temple is a Sōtō Zen Buddhist temple, and the people who have been helping him are other young monks from the temple and people from the local area. These were the people who were active in doing such work. 
Monk Abe goes by the hiragana nickname, "Monk Tsururin," but his real name is composed of the kanji for "crane" and "grove." Monk Tsururin has involved himself in these issues with the local people in complete accordance with his beliefs.

It's that kind of temple. They laid out the plans inside the main hall of the temple and made preparations. They are young monks. We watched the activities of these young monks, who are in their thirties, with very mixed feelings. Of course, we were concerned for them. There were some among them who could have children in the future.

That is why we thought it was absolutely imperative to have senior citizen volunteers, but it was difficult to bring this idea to fruition.

This is what Monk Tsururin said at the time. It was around the beginning of 2012. He said that he had mixed feelings when he tried to give people gifts. He wondered if they would take the gifts or if they would throw them away somewhere. While he was distressed about this, there were some monks who were active with the local people. It wasn't just Buddhist monks. There were Protestant ministers and probably all kinds of people who were doing this kind of steady, honest work.

\section{Summary of the Non-ethical Nature of Nuclear Power}

I think we have now come to have some degree of a coherent opinion on the unethical nature of nuclear power after all of this. First, these kinds of accidents lead to catastrophic results.

This is something that Takagi Jinzaburō has been saying for some time, but it is certain that something catastrophic will happen at some point and all we can do is imagine what that catastrophe will be. If we say something, we are scolded for crying wolf. If such a thing does happen, terrible things result. A "culture of death" occurs.

I think it would be more appropriate to say that we have a "culture of divisiveness" today, and an anxiety over the future that we can never shake off. What is going to happen? We live with the distress of being unable to foresee the future.

And "harm and considerable risk affect certain people." This is the sacrifice. The one who argues this point coherently is the physicist, Professor Ikeuchi Satoru. His arguments can be summarized into three points. The first is coercion of local areas. These are regions on the margins with no village industries. Such areas are targeted for the construction of nuclear power plants. Then the nuclear power plant people sweeten the deal to increase the number of supporters. There are inevitably those who oppose the power plants, so that's where the divisiveness is caused. That's where the supporters throw large amounts of all different kinds of money at it. But once an acci- 
dent happens, damage extends to that entire region, and as we found out this time, even to a far wide-ranging area.

Second, there are the laborers who are involved. There are many of these people, including those who are at the nuclear power plants, processing uranium and reprocessing. This time there are also people involved in decontamination. The concern now is that the number of laborers will fall short. The number needed each day to do the work is several thousand, perhaps six thousand. It's beyond our imagination to think of just how many decades this will continue.

It is expected that there will be health problems from this. The subcontracting is very complex so we do not know if the health damage can actually be tracked or not.

The third point is future generations. We must think of several thousand or tens of thousands of years. People in the future will truly receive no benefit at all from nuclear power. If anything, they will bear the brunt of the negative aspects and will be compelled to make tremendous efforts in order to protect themselves against harm. This can only be described as an outrage. Professor Ikeuchi's argument is comprised of these three points; that is, he discusses the coercion or the sacrifice that will occur.

What I have been emphasizing is the splintering of society caused by nuclear power, as well as the corruption and loss of trust caused by money and power. I'm talking about reports from industry, government, finance, and academia. Even academics and journalists are included in generating reams of deception and lies. Scholars bought off by the government as a group hold peculiar ideas based on certain beliefs that they put out continuously as if they were objective. I think this is the problem with radiation.

For people who profit from nuclear power it seems like a good thing, but there are always people who do not benefit. I think this structure of conflict is characteristic of nuclear power. It is destroying the base and foundation of trust in society. Local people do not put much confidence in academia, the current government, bureaucrats, or industry. Large newspapers are on the side of government and industry. In contrast, local newspapers tend to be critical. This is what has happened and so society has become fractured as a result.

I don't think there was much of this in Germany. I am focusing on the fact that even then, Germany overcame the structure of division through abandoning nuclear power. I think this is a very important point of view.

I mentioned this a few minutes ago, but sometimes when I say, "It's money over life, isn't it," there are people who understand and agree. That is, in regional communities, people support each other's lives. Within that construct there is the environment, communities, and the life of each individual. And 
then there is the profit that is derived from making calculations on computers through a tremendous profit structure. That is why things that look like insignificant damage are ignored.

Actually, those calculations are extremely dubious, but when people give numerical value to things, there is room for duplicity. That is what I think is happening.

In June, 2011, Murakami Haruki was one of the first to make an observation like that in his speech in Catalonia. Japanese made a momentous mistake. After the war we said "we will never repeat the mistake," but we have been making light of our pledge. Why is that? For efficiency. That's what Murakami said.

Because we put our efforts into economic development, we still do not fully understand the importance of what we experienced in the war. I think we are now back at the point with Fukushima whereby we can grasp what we failed to notice during the process of Japan's modernization.

\section{How Should We Accept Natural Disasters?}

Lastly, what I will talk about next we can understand through what I've already said about nuclear power. The damage from nuclear power on the Sanriku coast was not that big, but it was felt within the construct of damage from the tsunami. What I am quoting here is what people from the Konkō-kyō sectarian Shinto church in Tokyo said in an article in the Konkō Shinbun as things stood in 2011.

One mother explained the disasters to her child as the earth sneezing and passing gas. We are allowed to live thanks to the blessings of heaven and earth, but we humans have presumed to rearrange nature to make it more user-friendly for ourselves. But when the earth suddenly trembled, there was a big tsunami.

This explanation does not use the concept of God, and does not say that our religion teaches us such-and-such so things are this way. But I do think this explanation teaches us something important.

If the theory of divine punishment is true, I think this view would be far off the mark. But in Buddhism there is the term "true dharma," which refers to the idea that if you turn your back on the natural law, you will also upset nature. I think this concept is also in Confucianism.

What's different between this and divine punishment is that the person who suffers is not responsible for that suffering. Humanity is responsible for derailing society overall. We are part of that, too. We must learn to reexamine this idea. It is a notion in the Japanese religious perspective that fits the situation exactly.

After the disaster, Miyazawa Kenji’s poem, "Ame ni mo makezu" (Be 
Not Defeated by the Rain) was often cited. Actually, the "fool" character in this poem is the Jofukyo Bosatsu (Sadāparibhūta Bodhisattva) in the Lotus Sutra. Miyazawa Kenji's notes about this were found in his notebook after his death. The problematic issue in the poem is the word, man (慢). This is the man of zojōman (増上慢) or “conceited Zen." The image is how the Jofukyo Bosatsu, the Bodhisattva who is always disparaged, manages never to disparage anyone himself.

Thus, while we recognize that we have been extremely hubristic, we have been given a clue to how modern civilization, including our having had the atomic bomb dropped on us because of the war, and then our developing nuclear power within that civilization, has erred. This is not just about nuclear power; it includes the tsunami. I think we must recognize that the building of that colossal levee must be considered as part of the same problem.

Many symposia have been held at a variety of venues since 2011 . The religious world also became deeply aware of the issue. Unless it can be said that personal spirituality and what happens in society are unrelated, we have to move from considering spirituality simply as a personal affair and reconsider the issue from the opposite angle, that is, as an ethical issue that occurs in society and as a problem of spiritual culture. I think this is also what society demands and what the religious world is attempting to address. 